\title{
Eating location is associated with the nutritional quality of the diet in Norwegian adults
}

\author{
Jannicke B Myhre*, Elin B Løken, Margareta Wandel and Lene F Andersen \\ Department of Nutrition, Institute for Basic Medical Sciences, University of Oslo, PO Box 1046 Blindern, \\ 0317 Oslo, Norway
}

Submitted 23 May 2012: Final revision received 29 November 2012: Accepted 3 January 2013: First published online 12 March 2013

\begin{abstract}
Objective: To study the association between dinner eating location and the nutritional quality of the specific dinner meal and the whole-day dietary intake and to compare the diets of those consuming $\geq 25 \%$ of energy out of home and at school/work (SOH; substantial out-of-home eaters) with those consuming $<25 \%$ of energy out (NSOH; non-substantial out-of-home eaters).

Design: Cross-sectional dietary survey using two non-consecutive $24 \mathrm{~h}$ recalls. Recorded eating locations were at home, other private households, work/school, restaurant/cafeteria/fast-food outlet and travel/meeting.

Setting: Nationwide, Norway (2010-2011).

Subjects: Adults aged 18-70 years ( $n$ 1746).

Results: Dinners at restaurants and other private households were higher in energy than home dinners $(P<0 \cdot 01)$. Restaurant dinners contained less fibre $(\mathrm{g} / \mathrm{MJ}$; $P<0 \cdot 01)$ and had a higher percentage of alcohol consumers $(P<0 \cdot 05)$, while dinners at other private households had a higher percentage of energy from sugar $(P<0 \cdot 001)$ and a higher percentage of consumers of sugar-sweetened beverages $(P<0.05)$ than home dinners. Most differences between dinners consumed at different eating locations were also observed in dietary intakes for the whole day. SOH-eaters had a higher energy intake $(P<0 \cdot 01)$, a higher percentage of energy from sugar $(P<0 \cdot 01)$ and a lower fibre intake $(P<0 \cdot 01)$ than NSOH-eaters. The percentages of consumers of alcohol and sugar-sweetened beverages were higher $(P<0 \cdot 01)$ among SOH-eaters.

Conclusions: Dinner eating location was significantly associated with the nutritional quality of the diet, both for the specific dinner meal and for whole-day intake. Our data generally point to healthier dinners being consumed at home. SOH-eaters had a less favourable dietary intake than NSOH-eaters.
\end{abstract}

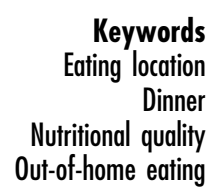

In the wake of increased standards of living and changing lifestyles, eating out of home has become increasingly common in Western societies. Although the majority of studies on the topic of eating location are from the $\mathrm{USA}^{(1,2)}$, increased consumption of food out of home has also been observed in Europe ${ }^{(3,4)}$. In Norway, household expenditure surveys show that restaurant spending has almost tripled since the beginning of the $1970 \mathrm{~s}^{(5)}$. These changes in eating pattern may have consequences for the quality of the diet. International studies have found that food eaten out of home tends to have a less healthy profile, e.g. a higher density of fat, saturated fat, sugar and alcohol, than food consumed at home ${ }^{(4,6,7)}$. Eating out of home has also been associated with obesity and weight gain $^{(8-11)}$. At the same time, the quality of food eaten out of home is likely to vary according to the specific location where it is consumed, and these associations may vary between countries. For instance, a Finnish study showed that employees who had lunch at a staff canteen were more likely to follow recommended food habits compared with other individuals ${ }^{(12)}$, while a study from Oslo, Norway found that frequent use of staff canteens was associated with unhealthy dietary habits and obesity ${ }^{(13)}$.

Data about eating location and consequences for the nutritional quality of the diet in Europe are quite limited ${ }^{(3,4)}$, and this research area has not been investigated in the general adult population in Norway. Due to the increased trend of eating out and the risk of reducing the nutritional quality of the diet, more information about the association between eating location and dietary intake is needed. In addition to eating location, also the type of meal consumed will influence nutritional quality ${ }^{(14)}$. The dinner meal has traditionally been the main hot meal in the Norwegian diet and the single largest contributor to intakes of energy, vegetables, meat and fish ${ }^{(15)}$. The purpose of the present paper was to investigate the association between dinner 
eating location and the nutritional quality of the diet, both for the specific dinner meal and for the total diet. Moreover, we wished to compare those who consumed a high percentage of their energy intake out of home with those who consumed less energy out.

\section{Methods}

\section{Design and study population}

A nationally representative sample ( $n$ 5000) of the Norwegian population aged 18-70 years was selected from the National Register and invited to participate in the Norkost 3 survey in 2010-2011. Persons born in Norway, Denmark or Sweden and residing in Norway were included. Participants completed two telephone-administered $24 \mathrm{~h}$ dietary recalls approximately four weeks apart. The first recall also included questions about non-dietary variables such as composition of the household, educational level, employment situation, height, weight and interest in a healthy diet. Participants completing the study were offered a standardized feedback on their $24 \mathrm{~h}$ recalls and every 25 th respondent received $3000 \mathrm{NOK}$ (\$US 500). Of the 5000 invited, 153 were unavailable for contact. In total, 1787 participants completed two $24 \mathrm{~h}$ recalls resulting in a participation rate of $37 \%$. For the analyses presented herein, forty-one participants were excluded because of missing information on some of the background variables. For analyses involving dinner eating location, the following were excluded: sixteen dinners due to consumption of multiple dinners at different locations on the same day, thirty-eight dinners consumed at 'unknown' or 'other locations' due to the low number of observations, and dinner from one man due to an energy intake of more than $20 \mathrm{MJ}$ from dinner. This resulted in the inclusion of 3228 dinners from 1725 participants. For the comparison of high and low consumers of out-of-home foods, all participants with complete information on the background variables were included ( $n$ 1746). The study was conducted according to the guidelines laid down in the Declaration of Helsinki and all procedures involving human subjects were approved by the Regional Committee for Medical Research Ethics. Verbal informed consent was obtained from all participants and was witnessed and formally recorded.

\section{Assessment of dietary intake and eating location}

The $24 \mathrm{~h}$ recalls aimed to include all foods and beverages consumed in the period between waking up on the preceding day and waking up on the day of the interview. The interviews were performed by trained personnel using an in-house data program (KBS version $7 \cdot 0$ ). Before starting the recall, the interviewer recorded whether the participant regarded the previous day as a normal day with regard to food and beverage intake ('yes' or 'no, variable'). The recall was performed as a three-step process. The first step reviewed the previous day's eating and drinking occasions including meal type, time and location of the meal and a brief description of the food consumed. Each eating or drinking occasion was defined by the respondent as either 'breakfast', 'lunch', 'dinner', 'supper', 'snack', 'beverage only' or 'dietary supplement only'. The predetermined locations were: 'home'; 'other private household'; 'work or school, including work/school canteens' (hereafter called 'work' due to the adult study population); 'restaurants, cafés, fast-food outlets' (hereafter called 'restaurant'); 'meeting, travel, during exercise' (hereafter called 'travel/meeting'); 'other location'; or 'unknown location'. Eating location was defined as the place of consumption irrespective of the place of purchase or preparation. The second step included detailed information about the food and portion sizes. The amounts of food consumed were quantified by household measures and a booklet containing photographs of foods in different portion sizes. The third step consisted of a checklist of commonly forgotten food items.

\section{Background variables}

BMI was calculated, based on self-reported weight and height, as weight in kilograms divided by the square of height in metres. Educational level was originally in eight categories, but was regrouped into two categories: 'high school, technical school, trade school or lower'; and 'university or college education'. Employment situation was originally in eight categories, but was regrouped into four categories: 'working' (including maternity/paternity leave and military service); 'not working' (homemaker, unemployed, disability, long-term sick leave); 'student'; and 'retired'. Household composition was originally in seven categories but was regrouped into three groups: 'single household'; 'living with adults' (partner/spouse, parents, other adults and other kind of household); and 'living with children' (with or without partner/spouse). Finally, participants were classified according to their interest in a healthy diet. From the original five categories two categories were made: 'no/very little interest, little interest and moderate interest'; and 'large interest or very large interest'. Weekdays were defined as Monday to Thursday and weekend days as Friday to Sunday.

\section{Definition of substantial out-of-bome eating}

For the comparison of participants consuming a high or low percentage of energy intake out of home, we defined substantial out-of-home ( $\mathrm{SOH}$ ) eaters as participants who consumed on average $\geq 25 \%$ of their daily energy intake out of home and work, while non-substantial out-of-home (NSOH) eaters consumed $<25 \%$ of their daily energy intake in locations other than the household premises and work. The home location was grouped together with work as it is quite common to bring sandwiches from home for lunch in Norway. Hence, restaurants, other private homes, travel/meeting, other location and unknown location were grouped as eating out of home. The average percentage of 
energy consumed out of home/work was calculated for each participant based on two recall days.

\section{Nutrient and food group analysis}

The food and nutrient intakes were estimated from the $24 \mathrm{~h}$ recalls using our calculation system KBS version $7 \cdot 0$. The database is based on the Norwegian Food Composition Table from $2006^{(16)}$ and is supplemented with additional food items from reliable sources. Intakes of macronutrients are presented as percentage contribution to total energy intake (E\%), while fibre is presented as g/MJ. Dietary supplements were excluded from all calculations.

For the food group 'fish', all kinds of fish including fish in sandwich spreads and composite dishes were included. Shellfish were not included. The food group 'meat' included all kinds of meats including meat products such as sausages, meatballs and cold cuts. The reported weights for both fish and meat refer to amounts of raw/unprepared foods. The food group 'vegetables' included all kinds of vegetables such as fresh, frozen or canned vegetables and vegetables in composite dishes, excluding legumes and potatoes. The food group 'sugar-sweetened beverages' consisted of sodas and cordials containing added sugars.

\section{Statistical analyses}

Statistical analyses were carried out separately for men and women, using the statistical software package IBM SPSS Statistics version 19. All tests were two-sided, and a significance level of 0.05 was chosen.

For the comparison of dinner meals and whole-day intakes according to dinner eating location, repeated observations were available for the majority of the participants because of consumption of dinner on both interview days. Mixed models were used to adjust for this dependency in the data by adding a variance component (random effect) for participants. Dinner and whole-day intakes of the continuous variables (energy, protein, fat, carbohydrates, added sugar, fibre, meat and vegetables) were analysed according to dinner eating location using linear mixed models adjusting for BMI, age, household composition, employment situation, educational level, season, interest in a healthy diet, normal day or not, and weekday or weekend day. Results are presented as adjusted means with 95\% confidence intervals. Due to a large number of participants not consuming alcohol, fish and sugar-sweetened beverages during the recall days, intakes were treated as binomial (consumer/non-consumer) variables and analysed using generalized mixed models with logit link. The models were otherwise the same as for the continuous variables. For the binomial variables, results are presented as percentage of dinners, or recording days, containing fish, alcohol or sugar-sweetened beverages with 95\% confidence intervals. All significance tests were done with the eating location 'home' as the reference category.

The $\chi^{2}$ test was used to test differences between SOH- and NSOH-eaters for the background variables expressed as percentages (education, family situation, employment situation, interest in a healthy diet and percentage of meals consumed out of home/work), while a $t$ test for independent samples was used for comparing differences in the continuous background variables age and BMI (presented as means and 95\% confidence intervals). Differences in dietary intake between $\mathrm{SOH}$ - and $\mathrm{NSOH}$-eaters were explored using linear regression for the continuous variables adjusting for BMI, age, household composition, employment situation, educational level and interest in a healthy diet. Results are presented as adjusted means, with $95 \%$ confidence intervals, and $P$ values for differences between $\mathrm{SOH}-$ and $\mathrm{NSOH}-$ eaters. For the binomial variables, logistic regression was used, but the analyses were otherwise the same as for the continuous variables. Results are presented as percentage consumers, with 95\% confidence intervals, and $P$ values for differences between $\mathrm{SOH}$-and $\mathrm{NSOH}-$ eaters.

\section{Results}

\section{Dinner eating location and dietary composition}

Table 1 presents background characteristics of the participants in the analyses of dinner eating location and dietary composition ( $51 \%$ women).

The majority of dinners (82\%) were consumed at home. Out-of-home dinners were most commonly consumed visiting other private households (7\%) and at restaurants (6\%). On average, $34 \%$ of the daily energy intake came from dinner.

Table 2 presents dietary composition of the dinner meal in relation to dinner eating location. Mean energy intake from dinner ranged from $3.4 \mathrm{MJ}$ at a travel/meeting to $4.6 \mathrm{MJ}$ at other private households for men and from $2 \cdot 7 \mathrm{MJ}$ at work to $3 \cdot 4 \mathrm{MJ}$ at restaurants for women.

For both genders, dinners eaten at restaurants and other private households were higher in energy than home dinners. Restaurant dinners had a lower fibre density and a higher proportion of alcohol consumers than dinners at home for both men and women. For men, the $\mathrm{E} \%$ from added sugar was also higher in restaurant dinners than in home dinners. Both genders had a higher $\mathrm{E} \%$ from added sugar when having dinner at other private households than when having dinner at home.

Men had higher intakes of meat when having dinner at other private households than at home, while women had higher meat intake when having dinner at a restaurant than when having dinner at home. Compared with home dinners, sugar-sweetened beverages were more often consumed with dinners at other private households and at restaurants for men; this was also found for dinners at other private households for women.

Table 3 shows whole-day intakes in relation to dinner eating location. Both genders had a higher total energy intake on days when having dinner at other private 
Table 1 Characteristics of the study participants included in analyses of dietary intake according to dinner eating location: Norwegian adults aged 18-70 years, Norkost 3 survey, 2010-2011

\begin{tabular}{|c|c|c|c|c|}
\hline \multirow[b]{2}{*}{ Characteristic } & \multicolumn{2}{|c|}{ Men $(n 850)$} & \multicolumn{2}{|c|}{ Women ( $n$ 875) } \\
\hline & Norkost 3 & $\begin{array}{l}\text { General Norwegian } \\
\text { population }{ }^{(33-35)}\end{array}$ & Norkost 3 & $\begin{array}{c}\text { General Norwegian } \\
\text { population }^{(33-35)}\end{array}$ \\
\hline \multicolumn{5}{|l|}{ Age group (\%) } \\
\hline $18-29$ years & 16 & 23 & 15 & 23 \\
\hline $30-39$ years & 16 & 20 & 19 & 20 \\
\hline $40-49$ years & 21 & 22 & 28 & 21 \\
\hline $50-59$ years & 22 & 19 & 21 & 19 \\
\hline $60-70$ years & 25 & 17 & 17 & 17 \\
\hline \multicolumn{5}{|l|}{ Educational levelt (\%) } \\
\hline High school or lower & 50 & 71 & 44 & 62 \\
\hline University or college & 50 & 29 & 56 & 38 \\
\hline \multicolumn{5}{|l|}{ Family situation $(\%)$} \\
\hline Single household & 18 & 22 & 16 & 16 \\
\hline Living with adults & 45 & 38 & 37 & 39 \\
\hline Living with children§ & 37 & 40 & 47 & 46 \\
\hline \multicolumn{5}{|l|}{ BMI (\%) } \\
\hline$<25 \mathrm{~kg} / \mathrm{m}^{2}$ & 40 & - & 61 & - \\
\hline$\geq 25 \mathrm{~kg} / \mathrm{m}^{2}$ & 60 & - & 39 & - \\
\hline \multicolumn{5}{|l|}{ Employment situation (\%) } \\
\hline Working & 73 & - & 74 & - \\
\hline Not working & 10 & - & 12 & - \\
\hline Student & 8 & - & 7 & - \\
\hline Retired & 9 & - & 6 & - \\
\hline \multicolumn{5}{|l|}{ Interest in healthy diet (\%) } \\
\hline No, low or moderate interest & 52 & - & 36 & - \\
\hline High or very high interest & 48 & - & 64 & - \\
\hline
\end{tabular}

tThe reference values for educational level in the general Norwegian population include individuals aged 20-66 years. $\ddagger$ The reference values for family situation in the general Norwegian population include individuals aged 16-66 years.

\$Participants living with children in the household, with or without other adults.

households than on days when having dinner at home. Men also had a higher total energy intake on days with a restaurant dinner, while women had a higher energy intake when having dinner at a travel/meeting than on days with home dinners. Men had a lower fibre density on days when having dinner at a restaurant and at other private households, while the $\mathrm{E} \%$ from added sugar was higher on days when having dinner at other private households compared with days with home dinners. For women, fibre density was lower on days when having dinner at a restaurant and at a travel/meeting while the E\% from added sugar was higher on days when having dinner at other private households compared with days when having dinner at home.

The percentage of days involving alcohol consumption was higher on days when dinner was consumed at a restaurant than when dinner was consumed at home among both men and women.

Men had a higher daily meat intake on days when having dinner at other private households than when having dinner at home, while women had a higher daily meat intake when having dinner at a restaurant than when having dinner at home. Whole-day intake of vegetables was lower when dinner was consumed at a travel/meeting for men and at a restaurant for women compared with days with home dinners. For men, the percentage of days with sugar-sweetened beverage consumption was higher when dinner was consumed at a restaurant and at other private households than on days when dinner was consumed at home.

To examine if differences in whole-day intakes were driven completely by differences in the dinner meal, the analyses were rerun with non-dinner intakes according to dinner eating location (data not shown). These analyses showed that men had higher non-dinner energy intakes on days when dinner was consumed at work, restaurants and at a travel/meeting than when dinner was consumed at home. Men also had a higher non-dinner $\mathrm{E} \%$ from fat on days when dinner was consumed at work or at a travel/meeting and a higher non-dinner $\mathrm{E} \%$ from protein on days when dinner was consumed at work than when dinner was consumed at home. The $\mathrm{E} \%$ from added sugar was higher and the fibre density was lower for non-dinner intakes on days when dinner was consumed visiting other private households compared with days with home dinner. Men also had a higher non-dinner meat intake when dinner was consumed at a travel/meeting than when dinner was eaten at home. For women, the only difference seen in non-dinner intakes according to dinner eating location was a higher non-dinner energy intake on days when dinner was consumed at a travel/meeting compared with days with home dinners.

\section{Comparison of substantial and non-substantial out-of-bome eaters}

Twenty-seven per cent of men and $29 \%$ of women were classified as SOH-eaters. Table 4 shows background 
Table 2 Intakest of energy, macronutrients and selected food groups for dinner meals consumed at different locations: Norwegian adults aged 18-70 years, Norkost 3 survey, 2010-2011

\begin{tabular}{|c|c|c|c|c|c|c|c|c|c|c|}
\hline & \multicolumn{10}{|c|}{ Dinner eating location } \\
\hline & \multicolumn{2}{|c|}{ Home } & \multicolumn{2}{|c|}{ Other private households } & \multicolumn{2}{|c|}{ Work $\ddagger$} & \multicolumn{2}{|c|}{ Restaurant } & \multicolumn{2}{|c|}{ Travel and meeting $\|$} \\
\hline & Mean & $95 \% \mathrm{Cl}$ & Mean & $95 \% \mathrm{Cl}$ & Mean & $95 \% \mathrm{Cl}$ & Mean & $95 \% \mathrm{Cl}$ & Mean & $95 \% \mathrm{Cl}$ \\
\hline Dinners ( $n$ 1590) consumed by men & \multicolumn{2}{|c|}{$(n$ 1321) } & \multicolumn{2}{|c|}{$(n 98)$} & \multicolumn{2}{|c|}{$(n 44)$} & \multicolumn{2}{|c|}{$(n 97)$} & \multicolumn{2}{|c|}{$(n 30)$} \\
\hline Energy (MJ/dinner) & $3 \cdot 6$ & $3 \cdot 4,3 \cdot 7$ & $4 \cdot 6^{\star \star \star}$ & $4 \cdot 2,5 \cdot 0$ & $3 \cdot 5$ & $2 \cdot 9,4 \cdot 0$ & $4 \cdot 2^{\star \star}$ & $3 \cdot 8,4 \cdot 5$ & $3 \cdot 4$ & $2 \cdot 8,4 \cdot 1$ \\
\hline Protein (E\%) & 23 & 22,24 & 23 & 21,25 & 22 & 19,25 & 21 & 19,23 & $17^{\star \star}$ & 13,21 \\
\hline Fat $(E \%)$ & 37 & 35,38 & 36 & 33,39 & 35 & 31,40 & 37 & 34,40 & 41 & 35,46 \\
\hline Carbohydrate (E\%) & 36 & 35,38 & 36 & 33,39 & 39 & 34,44 & 35 & 32,38 & 40 & 34,45 \\
\hline Added sugar (E\%) & 5 & 4,5 & $8^{* * *}$ & 6,9 & 6 & 4,9 & $7^{\star \star}$ & 5,9 & 6 & 3, 9 \\
\hline Fibre (g/MJ) & $2 \cdot 2$ & $2 \cdot 1,2 \cdot 3$ & $1 \cdot 9^{*}$ & $1 \cdot 6,2 \cdot 2$ & $2 \cdot 3$ & $1 \cdot 9,2 \cdot 7$ & $1 \cdot 6^{* * *}$ & $1 \cdot 3,1 \cdot 8$ & $2 \cdot 1$ & $1 \cdot 6,2 \cdot 6$ \\
\hline Dinners w/alcohol intake (\%) & 12 & 9,16 & 13 & 7,22 & 6 & 1,24 & $22^{\star}$ & 14,34 & 6 & 2,20 \\
\hline Vegetables (g/dinner) & 116 & 105,126 & 135 & 113,158 & 96 & 62,129 & 95 & 73,118 & $43^{\star \star \star}$ & 4,82 \\
\hline Meat and meat products (g/dinner) & 124 & 112,136 & $172^{\star \star}$ & 145,198 & 140 & 101,179 & 148 & 121,174 & 101 & 55,147 \\
\hline Dinners w/fish intake (\%) & 17 & 14,21 & 14 & 8,23 & 9 & 4,21 & 15 & 9,25 & 17 & 7,34 \\
\hline Dinners w/intake of SSB (\%) & 9 & 7,12 & $17^{*}$ & 11,26 & 15 & 8,28 & $21^{\star \star \star}$ & 14,31 & 16 & 6,34 \\
\hline Dinners ( $n$ 1638) consumed by women & \multicolumn{2}{|c|}{$(n 1331)$} & \multicolumn{2}{|c|}{$(n 127)$} & \multicolumn{2}{|c|}{$(n 55)$} & \multicolumn{2}{|c|}{$(n 93)$} & \multicolumn{2}{|c|}{$(n 32)$} \\
\hline Energy (MJ/dinner) & $2 \cdot 8$ & $2 \cdot 7,2 \cdot 9$ & $3 \cdot 2^{\star \star \star}$ & $3 \cdot 0,3 \cdot 5$ & $2 \cdot 7$ & $2 \cdot 3,3 \cdot 1$ & $3 \cdot 4^{* * *}$ & $3 \cdot 2,3 \cdot 7$ & $3 \cdot 0$ & $2 \cdot 6,3 \cdot 5$ \\
\hline Protein (E\%) & 24 & 23,25 & $21^{*}$ & 19,23 & 23 & 20,26 & 23 & 21,25 & 22 & 19,26 \\
\hline Fat $(\mathrm{E} \%)$ & 37 & 36,39 & 37 & 35,40 & 36 & 31,40 & 38 & 35,41 & 36 & 30,41 \\
\hline Carbohydrate (E\%) & 35 & 33,36 & 37 & 34,39 & 38 & 34,42 & 34 & 30,37 & 36 & 31,41 \\
\hline Added sugar (E\%) & 5 & 4,5 & $8^{\star \star \star}$ & 6,9 & 4 & 2,6 & 6 & 4,8 & 6 & 3,9 \\
\hline Fibre (g/MJ) & $2 \cdot 4$ & $2 \cdot 2,2 \cdot 6$ & $2 \cdot 3$ & $2 \cdot 0,2 \cdot 6$ & $2 \cdot 5$ & $2 \cdot 0,2 \cdot 9$ & $1 \cdot 8^{\star *}$ & $1 \cdot 5,2 \cdot 2$ & $2 \cdot 0$ & $1 \cdot 4,2 \cdot 5$ \\
\hline Dinners w/alcohol intake (\%) & 9 & 7,13 & 12 & 7,19 & 5 & 1,18 & $21^{\star *}$ & 13,32 & 18 & 8,36 \\
\hline Vegetables (g/dinner) & 111 & 102,120 & 111 & 94,129 & 95 & 69,121 & 96 & 76,116 & 83 & 50,116 \\
\hline Meat and meat products (g/dinner) & 100 & 92,109 & 107 & 90,124 & 92 & 66,118 & $131^{\star *}$ & 111,151 & 118 & 85,151 \\
\hline Dinners w/fish intake (\%) & 18 & 15,22 & 17 & 11,25 & 15 & 8,27 & 17 & 10,26 & 15 & 6,32 \\
\hline Dinners w/intake of SSB (\%) & 9 & 6,13 & $18^{\star \star}$ & 11,28 & 4 & 1,14 & 8 & 4,17 & 17 & 7,36 \\
\hline
\end{tabular}

$\mathrm{E} \%$, percentage of total energy intake; w, with; SSB, sugar-sweetened beverage.

Mean value was significantly different from that of dinners consumed at home (linear mixed model for absolute intakes and generalized linear mixed models for percentages): ${ }^{\star} P<0.05,{ }^{\star \star} P<0.01,{ }^{\star \star \star} P<0.001$.

tAdjusted means and $95 \%$ confidence intervals adjusted for age, BMI, family situation, educational level, employment situation, interest in a healthy diet, weekend day/weekday, season and if the day was a normal day or not with regard to food and beverage intake.

$\ddagger$ Work and school, including school/work canteens.

$\S$ Restaurant, fast-food outlet, café.

\|Travel, meeting, during exercise.

characteristics for SOH- and NSOH-eaters. For both genders, a lower percentage of SOH-eaters than NSOH-eaters reported living with children in the household, and the percentage of meals consumed out of home/work was higher for $\mathrm{SOH}$-eaters than for $\mathrm{NSOH}$-eaters.

The average contribution of out-of-home/work eating to total energy intake was $16 \%$ for men and $17 \%$ for women. Table 5 compares dietary intakes for $\mathrm{SOH}-$ and NSOH-eaters. Both male and female SOH-eaters had a higher total energy intake, a higher $\mathrm{E} \%$ from added sugar and a lower fibre density than NSOH-eaters. For both genders, the proportions of consumers of alcohol and sugar-sweetened beverages were higher for $\mathrm{SOH}$-eaters compared with NSOH-eaters.

Male SOH-eaters had a higher intake of meat than male NSOH-eaters, while the proportion of fish consumers was lower among SOH-eaters. For women, the intake of vegetables was lower for $\mathrm{SOH}$-eaters than for NSOH-eaters.

\section{Discussion}

The present study found that dinner eating location was associated with the nutritional quality of the diet, both for the specific dinner meal and for the total diet. Our data point to more healthful dinners being consumed at home than at any of the out-of-home locations. Dinners at work were an exception as no significant differences between these dinners and home dinners were observed. Mostly, the differences in composition between dinners consumed at various eating locations were also observed in the total daily intake. Persons consuming $\geq 25 \%$ of their energy intake outside home/work had a higher energy intake and a diet higher in added sugar and lower in dietary fibre than persons consuming less energy out.

\section{Dinner eating location and dietary composition}

To our knowledge, no previous studies have looked at the association between eating location and nutritional composition of the dinner meal specifically. However, a number of US and European studies have pointed to differences between foods consumed at home and out of home, most of them revealing mainly negative nutritional consequences of out-of-home eating ${ }^{(2,4,17)}$. Still, results from the $24 \mathrm{~h}$ recalls collected in the European Prospective Investigation into Cancer and Nutrition ${ }^{(18)}$ showed that the macronutrient composition of in- and out-of-home eating was quite similar in the Norwegian participants. This result may be explained by the fact that 
Table 3 Whole-day intakest of energy, macronutrients and selected food groups in relation to dinner eating location: Norwegian adults aged 18-70 years, Norkost 3 survey, 2010-2011

\begin{tabular}{|c|c|c|c|c|c|c|c|c|c|c|}
\hline & \multicolumn{10}{|c|}{ Dinner eating location } \\
\hline & \multicolumn{2}{|c|}{ Home } & \multicolumn{2}{|c|}{ Other private households } & \multicolumn{2}{|c|}{ Work‡ } & \multicolumn{2}{|c|}{ Restaurant§ } & \multicolumn{2}{|c|}{ Travel and meeting $\|$} \\
\hline & Mean & $95 \% \mathrm{Cl}$ & Mean & $95 \% \mathrm{Cl}$ & Mean & $95 \% \mathrm{Cl}$ & Mean & $95 \% \mathrm{Cl}$ & Mean & $95 \% \mathrm{Cl}$ \\
\hline Whole-day ( $n$ 1590) intake, men & \multicolumn{2}{|c|}{$(n 1321)$} & \multicolumn{2}{|c|}{$(n 98)$} & \multicolumn{2}{|c|}{$(n 44)$} & \multicolumn{2}{|c|}{$(n 97)$} & \multicolumn{2}{|c|}{$(n 30)$} \\
\hline Energy (MJ/d) & $10 \cdot 4$ & $10 \cdot 0,10 \cdot 8$ & $11 \cdot 8^{\star \star \star}$ & $11 \cdot 1,12 \cdot 6$ & $11 \cdot 5$ & $10 \cdot 3,12 \cdot 6$ & $11 \cdot 9^{* \star *}$ & $11 \cdot 2,12 \cdot 7$ & $11 \cdot 6$ & $10 \cdot 3,12 \cdot 9$ \\
\hline Protein (E\%) & 18 & 17,18 & 18 & 17,19 & 18 & 16,19 & $16^{*}$ & 15,17 & 16 & 14,18 \\
\hline Fat $(E \%)$ & 34 & 33,35 & 36 & 34,37 & 34 & 31,37 & 34 & 32,36 & $38^{*}$ & 35,41 \\
\hline Carbohydrate (E\%) & 43 & 43,44 & 43 & 41,45 & 44 & 41,47 & 42 & 40,44 & 43 & 39,46 \\
\hline Added sugar (E\%) & 8 & 7,8 & $10^{\star \star *}$ & 9,11 & 9 & 7,11 & 8 & 7,9 & 8 & 6,10 \\
\hline Fibre (g/MJ) & $2 \cdot 5$ & $2 \cdot 4,2 \cdot 5$ & $2 \cdot 1^{\star \star}$ & $2 \cdot 0,2 \cdot 3$ & $2 \cdot 4$ & $2 \cdot 1,2.7$ & $2 \cdot 1^{\star \star *}$ & $1 \cdot 9,2 \cdot 2$ & $2 \cdot 4$ & $2 \cdot 1,2 \cdot 7$ \\
\hline Days w/alcohol intake (\%) & 25 & 21,30 & 22 & 15, 32 & 25 & 13,43 & $43^{\star \star}$ & 32,54 & 29 & 15,48 \\
\hline Vegetables (g/d) & 156 & 143,170 & 162 & 133,190 & 128 & 85,171 & 141 & 112,169 & $101^{*}$ & 52,150 \\
\hline Meat and meat products $(\mathrm{g} / \mathrm{d})$ & 180 & 165,195 & $229^{\star \star}$ & 196,261 & 194 & 146,242 & 214 & 181,246 & 197 & 141,252 \\
\hline Days w/fish intake (\%) & 38 & 33,43 & 36 & 26,47 & 34 & 20,50 & 34 & 24,45 & 28 & 14,46 \\
\hline Days w/intake of SSB (\%) & 23 & 19,28 & $37^{*}$ & 27,49 & 31 & 19,47 & $34^{\star}$ & 24,45 & 38 & 21,58 \\
\hline Whole-day ( $n$ 1638) intake, women & \multicolumn{2}{|c|}{$(n 1331)$} & \multicolumn{2}{|c|}{ (n 127) } & \multicolumn{2}{|c|}{$(n 55)$} & \multicolumn{2}{|c|}{$(n 93)$} & \multicolumn{2}{|c|}{ (n 32) } \\
\hline Energy (MJ/d) & $8 \cdot 1$ & $7 \cdot 9,8 \cdot 4$ & $8 \cdot 8^{\star *}$ & $8 \cdot 3,9 \cdot 3$ & $8 \cdot 1$ & $7 \cdot 3,8 \cdot 8$ & $8 \cdot 5$ & $7 \cdot 9,9 \cdot 1$ & $9 \cdot 9^{* * *}$ & $9 \cdot 0,10 \cdot 8$ \\
\hline Protein (E\%) & 18 & 17,18 & 17 & 16,18 & 18 & 16,19 & 17 & 16,18 & 17 & 15,19 \\
\hline Fat (E\%) & 35 & 34,36 & 35 & 34,37 & 35 & 33,38 & 34 & 32,36 & 35 & 32,38 \\
\hline Carbohydrate (E\%) & 43 & 42,44 & 43 & 41,45 & 43 & 41,46 & 43 & 41,45 & 43 & 40,46 \\
\hline Added sugar (E\%) & 8 & 7,8 & $9^{* *}$ & 8,11 & 6 & 5,8 & 9 & 7,10 & 8 & 6,10 \\
\hline Fibre $(g / M J)$ & $2 \cdot 7$ & $2 \cdot 6,2 \cdot 8$ & $2 \cdot 5$ & $2 \cdot 3,2 \cdot 7$ & $2 \cdot 7$ & $2 \cdot 4,3 \cdot 0$ & $2 \cdot 4^{*}$ & $2 \cdot 2,2 \cdot 6$ & $2 \cdot 3^{\star}$ & $1 \cdot 9,2 \cdot 6$ \\
\hline Days w/alcohol intake (\%) & 19 & 15,23 & 22 & 15,31 & 15 & 7,30 & $28^{*}$ & 19,40 & 27 & 14,47 \\
\hline Vegetables (g/d) & 152 & 140,165 & 150 & 127,173 & 151 & 116,185 & $126^{\star}$ & 99,153 & 119 & 75,163 \\
\hline Meat and meat products $(\mathrm{g} / \mathrm{d})$ & 128 & 118,137 & 134 & 115,153 & 126 & 97,154 & $153^{*}$ & 131,176 & 148 & 111,184 \\
\hline Days w/fish intake (\%) & 35 & 31,40 & 34 & 25,43 & 31 & 20,46 & 38 & 28,49 & 39 & 23,57 \\
\hline Days w/intake of SSB\% & 19 & 15,23 & 26 & 18,36 & 10 & 4,23 & 14 & 7,24 & 29 & 14,49 \\
\hline
\end{tabular}

$\mathrm{E} \%$, percentage of total energy intake; $w$, with; SSB, sugar-sweetened beverage.

Mean value was significantly different from that of dinners consumed at home (linear mixed model for absolute intakes and generalized linear mixed models for percentages): ${ }^{\star} P<0.05,{ }^{\star \star} P<0.01,{ }^{\star \star \star} P<0.001$.

tAdjusted means and $95 \%$ confidence intervals adjusted for age, BMI, family situation, educational level, employment situation, interest in a healthy diet, weekend day/weekday, season and if the day was a normal day or not with regard to food and beverage intake.

$\ddagger$ Work and school, including school/work canteens.

ßRestaurant, fast-food outlet, café.

॥Travel, meeting, during exercise.

Table 4 Characteristics of substantial- and non-substantial out-of-home eaterst: Norwegian adults aged 18-70 years, Norkost 3 survey, 2010-2011

\begin{tabular}{|c|c|c|c|c|c|c|c|c|c|c|}
\hline \multirow[b]{3}{*}{ Characteristic } & \multicolumn{5}{|c|}{ Men $(n$ 858) } & \multicolumn{5}{|c|}{ Women ( $n$ 888) } \\
\hline & \multicolumn{2}{|c|}{$\mathrm{NSOH}$-eaters } & \multicolumn{2}{|c|}{ SOH-eaters } & \multirow[b]{2}{*}{$P \ddagger$} & \multicolumn{2}{|c|}{$\mathrm{NSOH}$-eaters } & \multicolumn{2}{|c|}{ SOH-eaters } & \multirow[b]{2}{*}{$P \ddagger$} \\
\hline & Mean & $95 \% \mathrm{Cl}$ & Mean & $95 \% \mathrm{Cl}$ & & Mean & $95 \% \mathrm{Cl}$ & Mean & $95 \% \mathrm{Cl}$ & \\
\hline & \multicolumn{2}{|c|}{ (n 624) } & \multicolumn{2}{|c|}{$(n$ 234 } & & \multicolumn{2}{|c|}{$(n 630)$} & \multicolumn{2}{|c|}{$(n$ 258) } & \\
\hline Age (years) & $47 \cdot 2$ & $46 \cdot 1,48 \cdot 3$ & $46 \cdot 0$ & $44 \cdot 0,47 \cdot 9$ & $0 \cdot 276$ & $45 \cdot 5$ & $44 \cdot 5,46 \cdot 5$ & $44 \cdot 1$ & $42 \cdot 4,45 \cdot 9$ & $0 \cdot 172$ \\
\hline $\mathrm{BMI}\left(\mathrm{kg} / \mathrm{m}^{2}\right)$ & $26 \cdot \overline{2}$ & $25 \cdot 9,26 \cdot 4$ & $26 \cdot 5$ & $26 \cdot 1,27 \cdot 0$ & $0 \cdot 162$ & $24 \cdot 6$ & $24 \cdot 3,25 \cdot 0$ & $24 \cdot 6$ & $24 \cdot 1,25 \cdot 1$ & 0.848 \\
\hline Educational level (\%) & & & & & $0 \cdot 190$ & & & & & 0.088 \\
\hline High-school or lower & 52 & & 47 & & & 46 & & 40 & & \\
\hline University or college & 48 & & 53 & & & 54 & & 60 & & \\
\hline \multicolumn{11}{|l|}{ Employment situation (\%) } \\
\hline Working & 74 & & 71 & & $0 \cdot 460$ & 76 & & 70 & & 0.086 \\
\hline Not working & 10 & & 9 & & 0.869 & 12 & & 13 & & $0 \cdot 647$ \\
\hline Student & 8 & & 9 & & 0.622 & 6 & & 10 & & 0.067 \\
\hline Retired & 9 & & 11 & & $0 \cdot 402$ & 6 & & 7 & & 0.599 \\
\hline \multicolumn{11}{|l|}{ Family situation (\%) } \\
\hline Single household & 17 & & 20 & & 0.332 & 15 & & 19 & & $0 \cdot 118$ \\
\hline Living with adults & 43 & & 50 & & 0.078 & 36 & & 39 & & $0 \cdot 313$ \\
\hline Living with children§ & 40 & & 30 & & 0.010 & 50 & & 42 & & 0.034 \\
\hline Interest in healthy diet (\%) & & & & & 0.387 & & & & & 0.945 \\
\hline No, low or moderate interest & 53 & & 50 & & & 36 & & 36 & & \\
\hline High or very high interest & 47 & & 50 & & & 64 & & 64 & & \\
\hline Meals consumed out of home/work\| (\%) & 7 & & 37 & & $<0.001$ & 7 & & 36 & & $<0.001$ \\
\hline
\end{tabular}

$\mathrm{E} \%$, percentage of total energy intake; SSB, sugar-sweetened beverage.

tNSOH-eaters (non-substantial out-of-home eaters): $<25 \%$ of total energy intake consumed out of home/work based on two $24 \mathrm{~h}$ recalls; SOH-eaters (substantial out-of-home eaters): $\geq 25 \%$ or more of total energy intake consumed out of home/work based on two $24 \mathrm{~h}$ recalls.

fUsing the $t$ test for independent samples for continuous variables and the $\chi^{2}$ test for variables expressed as percentages.

$\S$ Participants living with children in the household, with or without other adults.

॥The eating location 'work' also includes meals eaten at school and in work and school canteens. 
Table 5 Comparison of dietary intakest for substantial- and non-substantial out-of-home eatersł: Norwegian adults aged 18-70 years, Norkost 3 survey, 2010-2011

\begin{tabular}{|c|c|c|c|c|c|c|c|c|c|c|}
\hline & \multicolumn{5}{|c|}{ Men $(n 858)$} & \multicolumn{5}{|c|}{ Women ( $n$ 888) } \\
\hline & \multicolumn{2}{|c|}{$\mathrm{NSOH}$-eaters } & \multicolumn{2}{|c|}{ SOH-eaters } & \multirow[b]{2}{*}{$P \S$} & \multicolumn{2}{|c|}{$\mathrm{NSOH}$-eaters } & \multicolumn{2}{|c|}{ SOH-eaters } & \multirow[b]{2}{*}{$P \S$} \\
\hline & Mean & $95 \% \mathrm{Cl}$ & Mean & $95 \% \mathrm{Cl}$ & & Mean & $95 \% \mathrm{Cl}$ & Mean & $95 \% \mathrm{Cl}$ & \\
\hline & \multicolumn{2}{|c|}{$(n$ 624) } & \multicolumn{2}{|c|}{ (n 234) } & & \multicolumn{2}{|c|}{$(n 630)$} & \multicolumn{2}{|c|}{$(n 258)$} & \\
\hline Energy $(\mathrm{MJ} / \mathrm{d})$ & $10 \cdot 4$ & $10 \cdot 0,10 \cdot 8$ & $11 \cdot 1$ & $10 \cdot 6,11 \cdot 6$ & 0.006 & $7 \cdot 7$ & $7 \cdot 4,8 \cdot 0$ & $8 \cdot 4$ & $8 \cdot 1,8 \cdot 8$ & $<0.001$ \\
\hline Protein (E\%) & 18 & 17,18 & 17 & 16,17 & 0.002 & 18 & 17,18 & 17 & 16,17 & $<0.001$ \\
\hline Fat (E\%) & 34 & 33,35 & 34 & 33,35 & $0 \cdot 710$ & 34 & 33,35 & 35 & 34,36 & 0.037 \\
\hline Carbohydrate (E\%) & 44 & 43,45 & 43 & 42,44 & 0.224 & 44 & 43,45 & 43 & 42,44 & 0.014 \\
\hline Added sugar (E\%) & 7 & 6,8 & 9 & 8,10 & $<0.001$ & 7 & 7,8 & 9 & 8,9 & $<0.001$ \\
\hline Fibre $(g / M J)$ & $2 \cdot 6$ & $2 \cdot 5,2 \cdot 7$ & $2 \cdot 2$ & $2 \cdot 1,2 \cdot 3$ & $<0.001$ & $3 \cdot 0$ & $2 \cdot 9,3 \cdot 1$ & $2 \cdot 4$ & $2 \cdot 3,2 \cdot 6$ & $<0.001$ \\
\hline Alcohol ( $\%$ consumers) & 31 & 25,36 & 47 & 40,55 & $<0.001$ & 21 & 17,26 & 37 & 30,45 & $<0.001$ \\
\hline Meat and meat products & 165 & 152,179 & 199 & 181,217 & $<0.001$ & 115 & 106,124 & 124 & 113,135 & $0 \cdot 130$ \\
\hline Vegetables (g/d) & 154 & 141,166 & 146 & 130,162 & 0.365 & 157 & 145,169 & 135 & 121,150 & 0.004 \\
\hline Fish (\% consumers) & 68 & 62,73 & 57 & 49,65 & 0.006 & 57 & 51,63 & 56 & 49,64 & 0.930 \\
\hline SSB ( $\%$ consumers) & 35 & 29,41 & 50 & 42,58 & $<0.001$ & 22 & 17,28 & 34 & 27,43 & 0.001 \\
\hline
\end{tabular}

$\mathrm{E} \%$, percentage of total energy intake; SSB, sugar-sweetened beverage.

tAdjusted means and confidence intervals (two $24 \mathrm{~h}$ recalls) adjusted for age, BMI, family situation, educational level, employment situation and interest in a healthy diet.

¥NSOH-eaters (non-substantial out-of-home eaters): $<25 \%$ of total energy intake consumed out of home/work based on two $24 \mathrm{~h}$ recalls; SOH-eaters (substantial out-of-home eaters): $\geq 25 \%$ or more of total energy intake consumed out of home/work based on two $24 \mathrm{~h}$ recalls.

$\S$ Using linear regression for continuous variables and logistic regression for binomial variables.

around half of the out-of-home eating consisted of eating at work ${ }^{(10)}$. Although many workplaces in Norway have staff canteens, it is still quite usual to bring packed food from home to work ${ }^{(13)}$. The composition of food brought from home to work is likely to be similar to that of food consumed at home, possibly contributing to diminishing a difference between in- and out-of-home eating.

There are also studies showing that different out-of-home eating locations may influence the quality of the diet in different directions ${ }^{(3,19)}$. The relationship between eating location and dietary quality may also vary between different countries as illustrated by the different associations between dietary quality and having lunch in a staff canteen seen in Finland and Norway ${ }^{(12,13,20)}$. Generalization of findings from one country to another will therefore need careful consideration of local circumstances.

There are several possible explanations why people may consume more energy and a less healthful diet when having dinner out of home compared with at home. Eating outside the home may be a way to mark a special occasion, where one may allow oneself different dietary choices from the usual ones. Moreover, it has been suggested that eating in larger groups may increase food consumption $^{(21)}$. Dinners at restaurants or in other private households may be occasions where more people are likely to be present. Other explanations for differences between restaurant and home dinners may be a greater availability of energy-dense foods, beverages and desserts, lack of healthy food options and lack of nutrition information about foods eaten out. The portion sizes may also be larger when eating out, contributing to a higher energy intake ${ }^{(22)}$.

In the present study, many of the differences in composition found between dinners consumed at various eating locations were also observed in corresponding intakes for the whole day, although these differences were not always completely explained by differences in the dinner meal. This points to the nutritional importance of the dinner meal and that changing its composition may have consequences for the nutritional quality of the diet as a whole. However, for women, whole-day energy intakes on days when having dinner at a restaurant were not higher than on days when having dinner at home, even though energy intake from restaurant dinners was significantly higher than energy intake from home dinners. This may be due to chance or the possibility that women to a larger extent than men down-regulate energy intake from the rest of the day when consuming more energy from a restaurant dinner. Other studies have found different effects of restaurant eating on BMI between men and women ${ }^{(10,23)}$. Further research will have to determine if gender differences exist in this area.

\section{Comparison of substantial and non-substantial out-of-bome eaters}

Several previous studies have compared dietary intakes in high and low consumers of out-of-home foods in the USA ${ }^{(1,24,25)}$, Australia ${ }^{(26)}$ and Europe ${ }^{(3,27)}$. Even though the definitions of out-of-home eating differ slightly and the criteria for being a high consumer of out-of-home foods are different between studies, the main tendency of a less healthful dietary intake in high consumers of out-of-home foods remains quite stable. This is in accordance with the differences observed between SOH- and NSOH-eaters from the present study. Our grouping of food eaten at work together with food eaten at home differs somewhat from definitions in other publications. If food eaten at work was included in the eating out category, $58 \%$ of 
both men and women were grouped as SOH-eaters. The only significant differences in dietary intake between $\mathrm{SOH}-$ and $\mathrm{NSOH}$-eaters using this definition were male SOH-eaters having a slightly lower $\mathrm{E} \%$ from protein and female SOH-eaters consuming somewhat less fibre/MJ (data not shown). Hence, for the Norwegian situation, it seems appropriate to look at food consumed at work separately from food from other out-of-home locations. This finding is similar to the aforementioned finding of Orfanos et al. ${ }^{(18)}$ of similar composition of home food and out-of-home food when grouping food eaten at work as out-of-home food and underlines the importance of acknowledging that different eating locations may be associated with different dietary intakes when studying out-of-home eating.

\section{Strengths and limitations}

A limitation of the present study is the low participation rate, with only $37 \%$ of the available invited sample completing two $24 \mathrm{~h}$ recalls. A comparison with whole-country statistics showed that participants were somewhat higher educated than the population in general. Participation was also lower in the youngest age groups. Previous studies have shown that people of lower socio-economic status are more likely to eat at fast-food restaurants ${ }^{(28,29)}$. Out-of-home eating has also been reported to occur more frequently in younger age groups ${ }^{(3,18)}$. Hence, the low participation rate may have contributed to underestimating the impact of out-of-home eating in our study.

Due to the mode of data collection, eating location was defined as the location of consumption rather than the location of preparation or purchase. This is in agreement with the definition used by Orfanos et $a l^{(18)}$ but different from that of Lin et al. ${ }^{(7)}$ and Burns et al. ${ }^{(26)}$, who defined location according to where the food was obtained. Our definition will result in meals prepared out of home (such as take-out meals) being classified according to where they were eaten. It has been estimated that about $28 \%$ of purchases in Norwegian restaurants (including fast-food outlets, pubs and cafés) are take-out foods ${ }^{(30)}$. Given the relatively low number of restaurant dinners compared with home dinners in our study, the number of take-out meals included in our data is likely to be quite small. Still, the misclassification introduced by take-out meals is expected to lessen differences between restaurant meals and home meals somewhat as some take-out foods may be included in the home meals.

Data for the present analyses were obtained from an observational study, and participants were not randomized to either home dinners or dinners at other locations. Hence, participants eating out may also prefer foods with lower nutritional quality when eating at home ${ }^{(31)}$ and there may be differences between people who eat out of home and those who do not that we have not been able to control for in the analyses. However, a comparison of dinners consumed at home by those who had two dinners at home and those who had one dinner at home and one dinner at a restaurant showed no significant differences in dinner energy intakes at home between the groups, suggesting that dietary intakes may not necessarily differ in general.

A strength of the present study is the comparison of specifically the dinner meal eaten at different locations. Comparisons of food in general consumed at different locations may be disturbed by the fact that different meal types differ in dietary composition ${ }^{(14,15)}$. Hence, if some meals are more commonly eaten out of home than others, this may lead to a comparison of different meal types (for instance breakfast $v$. dinner) that would be different regardless of eating location.

\section{Practical implications}

Reducing energy density ${ }^{(32)}$ and supplying more healthy options may be acceptable ways of modifying the nutritional quality of restaurant foods and other out-of-home foods. In Norway, focus has so far been placed on foods consumed in out-of-home locations such as kindergartens and work canteens, but no official guidelines aimed specifically at restaurants exist. Development of such guidelines may help increase knowledge and awareness of the importance of healthy eating among chefs.

\section{Conclusion}

Our data showed that dinner eating location was associated with the nutritional quality of the diet, both for the specific dinner meal and for whole-day dietary intake. Different out-of-home eating locations are likely to influence dietary intake in different ways. No differences in nutritional quality were seen between home dinners and dinners consumed at work, while restaurant dinners and dinners consumed at other private households generally had a less healthy dietary composition. Moreover, our study showed that persons consuming $\geq 25 \%$ of their energy outside home/work had a less favourable dietary intake than those consuming less energy out.

\section{Acknowledgements}

Sources of funding: This work was supported by the Research Council of Norway (grant number 199545). Conflicts of interest: The authors declare no conflict of interest. Authors' contributions: J.B.M. carried out the data analyses and drafted the first manuscript. E.B.L., M.W. and L.F.A. assisted and provided advice at all stages of the work. All authors have critically read and revised the paper. Acknowledgements: The authors are grateful to all participants in the Norkost 3 survey. They also wish to thank Øivind Skare who provided assistance with the statistical analyses. 


\section{References}

1. Kant AK \& Graubard BI (2004) Eating out in America, 1987-2000: trends and nutritional correlates. Prev Med 38, 243-249.

2. Guthrie JF, Lin BH \& Frazao E (2002) Role of food prepared away from home in the American diet, 1977-78 versus 1994-96: changes and consequences. J Nutr Educ Behav 34, 140-150.

3. Vandevijvere S, Lachat C, Kolsteren P et al. (2009) Eating out of home in Belgium: current situation and policy implications. Br J Nutr 102, 921-928.

4. O'Dwyer NA, Gibney MJ, Burke SJ et al. (2005) The influence of eating location on nutrient intakes in Irish adults: implications for developing food-based dietary guidelines. Public Health Nutr 8, 258-265.

5. Statistics Norway (2011) Household consumption. http:// www.ssb.no/en/inntekt-og-forbruk (accessed April 2011).

6. Loughridge JM, Walker AD, Sarsby H et al. (1989) Foods eaten outside the home: nutrient contribution to total diet. J Hum Nutr Diet 2, 361-369.

7. Lin BH \& Frazao E (1997) Nutritional quality of foods at and away from home. Food Rev 20, 33-40.

8. Bes-Rastrollo M, Basterra-Gortari FJ, Sanchez-Villegas A et al. (2010) A prospective study of eating away-from-home meals and weight gain in a Mediterranean population: the SUN (Seguimiento Universidad de Navarra) cohort. Public Health Nutr 13, 1356-1363.

9. Bezerra IN \& Sichieri R (2009) Eating out of home and obesity: a Brazilian nationwide survey. Public Health Nutr 12, 2037-2043.

10. Naska A, Orfanos P, Trichopoulou A et al. (2011) Eating out, weight and weight gain. A cross-sectional and prospective analysis in the context of the EPIC-PANACEA study. Int J Obes (Lond) 35, 416-426.

11. Bezerra IN, Curioni C \& Sichieri R (2012) Association between eating out of home and body weight. Nutr Rev 70, 65-79.

12. Roos E, Sarlio-Lahteenkorva S \& Lallukka T (2004) Having lunch at a staff canteen is associated with recommended food habits. Public Health Nutr 7, 53-61.

13. Kjollesdal MR, Holmboe-Ottesen G \& Wandel M (2011) Frequent use of staff canteens is associated with unhealthy dietary habits and obesity in a Norwegian adult population. Public Health Nutr 14, 133-141.

14. de Castro JM, Brewer EM, Elmore DK et al. (1990) Social facilitation of the spontaneous meal size of humans occurs regardless of time, place, alcohol or snacks. Appetite 15, 89-101.

15. Løken EB (1977) Kostens sammensetning ved forskjellige måltidstyper (Dietary composition of different meal types). Näringsforskning 21, 255-261.

16. The Norwegian Food Safety Authority, The Norwegian Directorate of Health \& The University of Oslo (2006) The Norwegian Food Composition Table 2006.

17. Kearney JM, Hulshof KF \& Gibney MJ (2001) Eating patterns temporal distribution, converging and diverging foods, meals eaten inside and outside of the home - implications for developing FBDG. Public Health Nutr 4, 693-698.
18. Orfanos P, Naska A, Trichopoulou A et al. (2009) Eating out of home: energy, macro- and micronutrient intakes in 10 European countries. The European Prospective Investigation into Cancer and Nutrition. Eur J Clin Nutr 63, Suppl. 4, S239-S262.

19. Larson N, Neumark-Sztainer D, Laska MN et al. (2011) Young adults and eating away from home: associations with dietary intake patterns and weight status differ by choice of restaurant. J Am Diet Assoc 111, 1696-1703.

20. Raulio S, Roos E \& Prattala R (2010) School and workplace meals promote healthy food habits. Public Health Nutr 13, 987-992.

21. Clendenen VI, Herman CP \& Polivy J (1994) Social facilitation of eating among friends and strangers. Appetite 23, 1-13.

22. Young LR \& Nestle M (2003) Expanding portion sizes in the US marketplace: implications for nutrition counseling. $J \mathrm{Am}$ Diet Assoc 103, 231-234.

23. Binkley JK, Eales J \& Jekanowski M (2000) The relation between dietary change and rising US obesity. Int J Obes Relat Metab Disord 24, 1032-1039.

24. Haines PS, Hungerford DW, Popkin BM et al. (1992) Eating patterns and energy and nutrient intakes of US women. J Am Diet Assoc 92, 698-704, 707.

25. Clemens LH, Slawson DL \& Klesges RC (1999) The effect of eating out on quality of diet in premenopausal women. J Am Diet Assoc 99, 442-444.

26. Burns C, Jackson M, Gibbons C et al. (2002) Foods prepared outside the home: association with selected nutrients and body mass index in adult Australians. Public Health Nutr 5, 441-448.

27. Orfanos P, Naska A, Trichopoulos D et al. (2007) Eating out of home and its correlates in 10 European countries. The European Prospective Investigation into Cancer and Nutrition (EPIC) study. Public Health Nutr 10, 1515-1525.

28. French SA, Harnack L \& Jeffery RW (2000) Fast food restaurant use among women in the Pound of Prevention study: dietary, behavioral and demographic correlates. Int J Obes Relat Metab Disord 24, 1353-1359.

29. Thornton LE, Crawford DA \& Ball K (2011) Who is eating where? Findings from the SocioEconomic Status and Activity in Women (SESAW) study. Public Health Nutr 14, 523-531.

30. Econ Pöyry (2008) Rapport 2008-006 Moms på serveringstjenester (Value added tax on food services). Oslo: Econ Pöyry AS.

31. Mancino L, Todd J \& Lin BH (2009) Separating what we eat from where: measuring the effect of food away from home on diet quality. Food Policy 34, 557-562.

32. Obbagy JE, Condrasky MD, Roe LS et al. (2011) Chefs' opinions about reducing the calorie content of menu items in restaurants. Obesity (Silver Spring) 19, 332-337.

33. Statistics Norway (2011) Population. https://www.ssb.no/ en/befolkning/statistikker/folkemengde (accessed November 2011).

34. Statistics Norway (2011) Education. https://www.ssb.no/ en/utdanning/statistikker/utniv (accessed November 2011).

35. Statistics Norway (2011) Families and households. http:// www.ssb.no/en/familie (accessed November 2011). 